Research Article

\title{
Investigation of Pressure Rise and Flame Acceleration Characteristics in a Single Channel of Wave Rotor Combustor with Spoilers
}

\author{
Jianzhong Li $\mathbb{D},{ }^{1}$ Kaichen Zhang, ${ }^{1}$ Wei $\mathrm{Li}^{2}{ }^{2}$ and Li Yuan ${ }^{3}$ \\ ${ }^{1}$ Key Laboratory of Aero-Engine Thermal Environment and Structure, Ministry of Industry and Information Technology, \\ Nanjing University of Aeronautics and Astronautics, 29 Yudao St., Nanjing 210016, China \\ ${ }^{2}$ AVIC Aviation Powerplant Research Institute, 1815 Rd., Zhuzhou 412002, China \\ ${ }^{3}$ School of National Defense Engineering, The Army Engineering University of PLA, 88 Biaoying Rd., Nanjing 210007, China
}

Correspondence should be addressed to Jianzhong Li; ljzh0629@nuaa.edu.cn

Received 23 November 2018; Accepted 1 April 2019; Published 2 May 2019

Academic Editor: Giovanni Delibra

Copyright (C) 2019 Jianzhong Li et al. This is an open access article distributed under the Creative Commons Attribution License, which permits unrestricted use, distribution, and reproduction in any medium, provided the original work is properly cited.

A simplified single channel wave rotor combustor (WRC) experimental rig was established, in which the spoilers with different blockage ratios (BR) could be conveniently installed and disassembled. The spoilers were firstly used for WRC to improve the pressure rise. The effects of different blockage ratios on the pressure rise and flame acceleration characteristics in a single channel of the WRC were investigated. The addition of spoilers could remarkably improve the pressure rise and flame propagation speed in a single channel of the WRC. While the blockage ratio of the spoiler increases, both pressure rise and mean flame propagation speed are improved. When the spoilers with a blockage ratio of $38.91 \%$ are used, the peak pressure increases by $200 \%$ compared to that of WRC without the spoilers. When the spoilers of different blockage ratios $(23.35 \%$, $31.13 \%$, and $38.91 \%$ ) are used, it is found that the flame propagation speed is significantly improved with the increasing of the blockage ratio. Specifically, the maximum flame propagation speed reaches $55 \mathrm{~m} / \mathrm{s}$, and the maximum mean flame propagation speed is $36.95 \mathrm{~m} / \mathrm{s}$. Furthermore, combustion becomes more intense, and the flame is brighter around the spoiler.

\section{Introduction}

For a gas turbine engine, pressure gain combustion has a strong potential to significantly improve the performance and reduce emissions [1]. The constant-volume pressure gain combustion could achieve an ideal Humphrey cycle. Under the same inlet conditions of a combustor, the pressure gain combustion is theoretically much more efficient than a conventional Brayton cycle, as shown in Figure 1. Because a lower entropy generation in the combustion process is achieved to improve higher work availability, the output power would be increased and the thermal efficiency of gas turbine engine may be increased by $30 \%-50 \%$ [2-4].

Wave rotor combustor (WRC) is an unsteady pressure gain combustion device [5-7]. The combination of WRC and gas turbine engine technologies have led to the formation of a new concept of engine exhibiting a series of advantages such as self-pressurization and high thermodynamic cycle efficiency and thus can significantly enhance system performance. Compared to other unsteady pressure gain combustion devices such as pulse detonation engines (PDEs) and pulse engines, the multichannel combination mode of a WRC can maintain intake and exhaust airflows in a quasistable state and enable stable propulsion. The unsteady flow and combustion processes of a WRC are very similar to PDE processes. A WRC can be considered as a reversed design of a rotary-valved multiple-tube PDE, in which the relative motion between combustor tubes and the inlet valve are achieved by rotating the tubes and fixing the inlet valve. The working process of a wave rotor combustor is described as follows, as shown in Figure 2. Firstly, the inlet of a channel opens and the outlet closes. The channel is mostly filled with some combustible mixture. Secondly, both the inlet and outlet close; the hot jet gas enters the channel to ignite the 




(a)



(b)

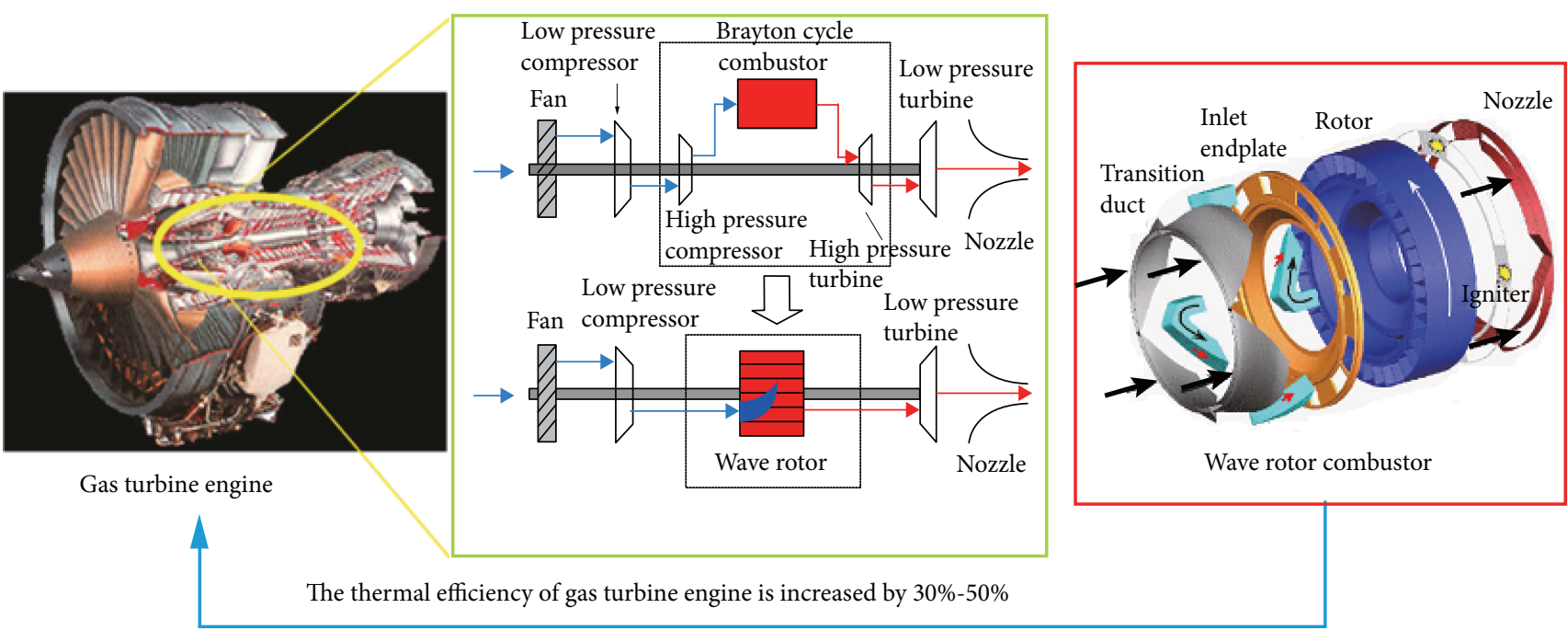

(c)

FIGURE 1: Comparison between the ideal Brayton cycle and the ideal Humphrey cycle on P-V diagram (a) and T-S diagram (b) WRC location in a turbojet engine $(c)$.

combustible fuel/air mixture. Thirdly, the constant-volume pressure gain combustion is achieved. Fourthly, the channel is filled with high-temperature and high-pressure burned gas, and then the outlet duct opens to discharge the burned gas. This is accompanied by the production of an expansion wave, which propagates upstream in the channel. Finally, the inlet duct opens to refill the combustible fuel/air mixture. The outlet duct closes and the inlet remains open, and then hammer shock waves are produced at the outlet. This process is also referred to the precompression process of the WRC. However, complex flow and combustion mechanisms are often associated with the WRC, in which there is a series of complex wave mainly involving the interaction of shock waves, pressure waves, expansion waves, and flames. For a multitube PDE, the outlet remains open at all times while the channels are periodically opened to the inlet port similar to the wave rotor configuration. Thus, no hammer shock is generated, and the fresh mixture inside the channels is only stopped by a fan of expansion waves generated by closing the inlet port. The numerical results presented later clearly show that the pressure rise behind the detonation wave is less than a wave rotor combustor due to the lack of a precompression wave and existence of the expansion [8-13].

Elharis et al. conducted a preliminary testing of a WRC using ethylene as fuel and a wave rotor speed of $2100 \mathrm{rpm}$ [1]. High-frequency dynamic pressure sensors were installed at different positions to measure the variation of pressure with time, and self-pressurized combustion was realized within the WRC. Further to this, Matsutomi et al. investigated the combustion characteristics of a WRC with an air flow rate of $9.6 \mathrm{lbm} / \mathrm{s}$, an acetylene flow rate of $0.51 \mathrm{lbm} / \mathrm{s}$, and a wave rotor speed of $2100 \mathrm{rpm}$, and variation of the total pressure was measured at both the inlet and the outlet [14]. Before ignition by hot jets, the rated inlet pressure was approximately $22.25 \mathrm{psi}$ and dropped by approximately 0.5 psi after ignition. During combustion, mean pressure at the inlet was approximately 26.9 psi and at the outlet approximately 18.1 psi. Chinnathambi et al. established a singlechannel WRC experimental rig to explore the effects of different fuels on ignition and flame propagation processes while neglecting filling and discharge of the gas mixture in 


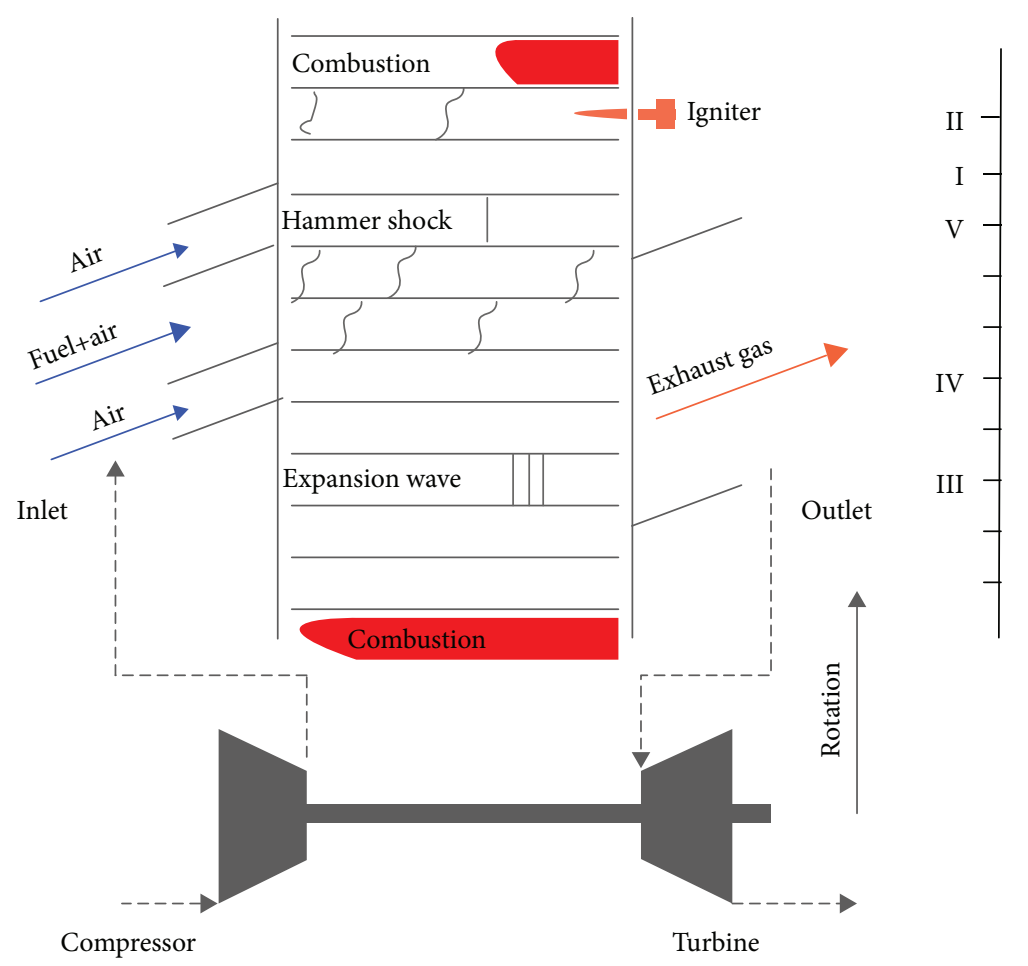

FIgURE 2: The schematic of the operating process for a WRC.

the WRC [15]. In addition, a precombustion chamber was used to generate hot jets for ignition. Compared to methane, ethylene can shorten the ignition delay time; moreover, a mixture of methane and hydrogen further shortens ignition delay times and accelerates flame propagation, thus achieving an optimal jet motion time of $6.1 \mathrm{~ms}$. In general, ethylene results in a maximum pressure of $50 \mathrm{psi}$, and propane has a maximum pressure of 30 psi. From publication reference, the pressure in the channel of a WRC is less than $0.8 \mathrm{MPa}$, and the length of a WRC is about $700 \mathrm{~mm}$. The length of the WRC is only $200 \mathrm{~mm}$ in this paper. To increase the pressure rise of the WRC, the technology of intensifying combustion should be explored.

To date, relatively few studies have explored combustion intensity in a WRC, whereas a large amount of research on detonation exists. Moreover, installing the Shchelkin spiral, an obstacle used to create a partial blockage within the denotation tube, has been found to accelerate the deflagration-todetonation transition (DDT) [16-19]. Lee et al. examined a number of parameters associated with the DDT process including the blockage ratio (BR) of the obstacle and spacing of obstacles for the combustion of ethylene and air using round plate obstacles in a square tube with a length of $1650 \mathrm{~mm}$ and width of $45 \mathrm{~mm}$ [20]. Based on planar laserinduced fluorescence (PLIF) imaging and Schlieren images, the position and spacing of obstacles were shown to affect the intensity of turbulence in the detonation chamber and enhance the acceleration of flames. In particular, local thermal explosions in the unburned mixture further accelerate the propagation of flames. The results revealed that DDT can only be achieved when the flame propagation speed is increased to half of the propagation speed of the ChapmanJouguet detonation wave, while a BR of $0.3 \sim 0.6$ can also effectively accelerate the propagation of flames. Cooper et al. [21] conducted similar tests and concluded that the DDT time for a mixture of ethylene, propylene, and oxygen can, on average, be reduced by $65 \%$ using a turbulence device with a BR of $43 \%$; however, propulsion is also simultaneously reduced by $25 \%$. Witt et al. [22] investigated the detonation technology based on two different types of intensified shock wave reaction devices, a plate/cone or annular orifice plate, using ethylene as fuel and oxygen diluted with nitrogen as an oxidizing agent. As the high-speed flame/shock waves interacted with obstacles, the DDT process was examined in a detonation tube with an inner diameter of $140 \mathrm{~mm}$ and length of $3100 \mathrm{~mm}$. For a mixture of ethylene and air with an equivalence ratio, the DDT process can be realized at a position $1320 \mathrm{~mm}$ away from the ignition position, i.e., detonation could be used to initiate the explosion. In addition, Zheng et al. experimentally investigated the shape, BR, and number and spacing of spoilers on the peak pressure of the detonation wave [23, 24]. Furthermore, by combining theoretical analysis with numerical simulations, Valiev et al. [25] examined the effects of the position and spacing of spoilers on the acceleration of flame propagation in a detonation tube and found flame propagation to be remarkably accelerated using spoilers. Further, flame acceleration dropped as the initial Mach number increased. Therefore, by referring to the intensified combustion measures in detonation combustion, spoilers can be installed in a WRC in order to accelerate the propagation of flames, promote conflagration, and almost achieve detonation combustion. In publication references, 


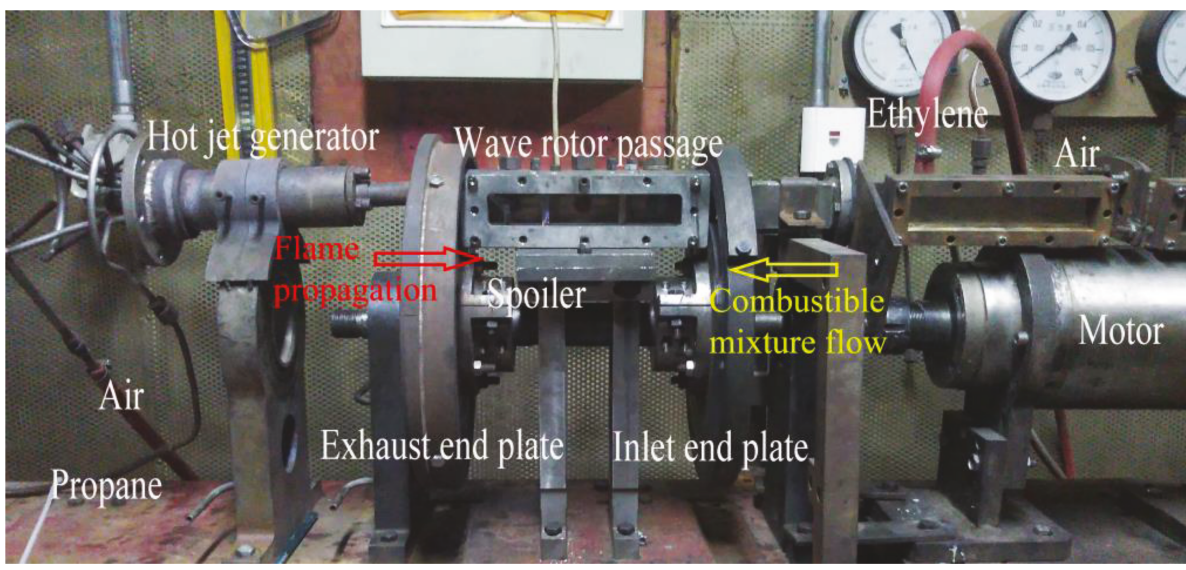

FIgURE 3: An experimental rig of a WRC.
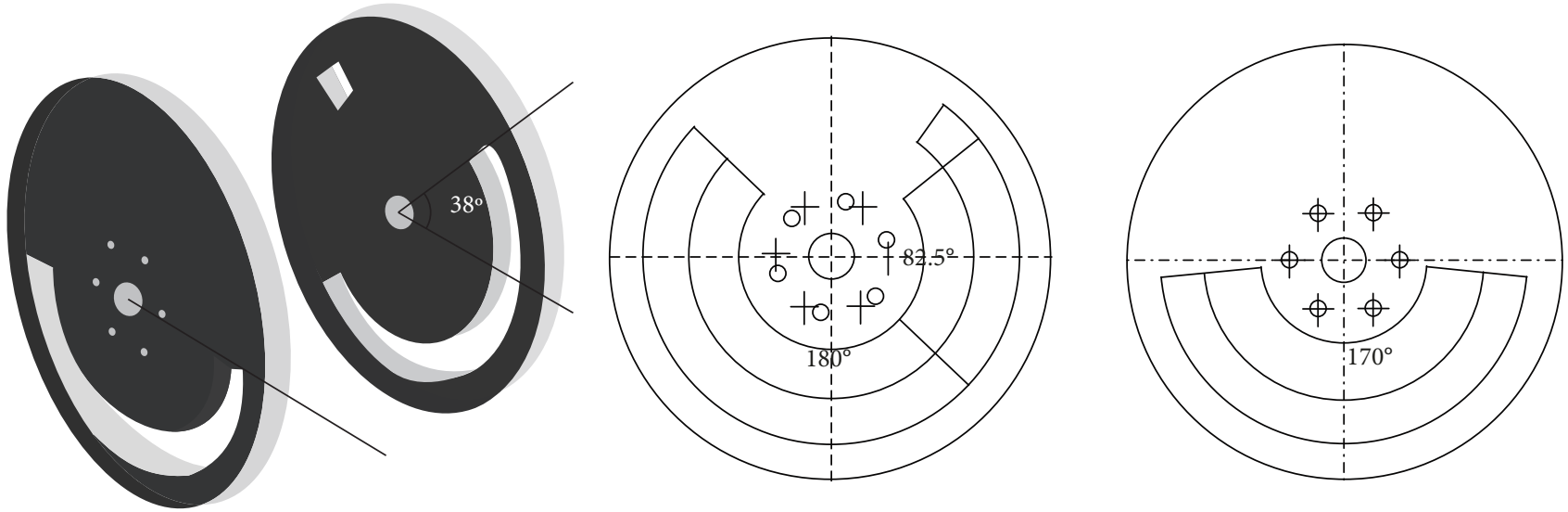

FIGURE 4: Illustration of the sealing disk structure on both sides of a WRC.

the spoilers were used to improve the pressure of PDE or shock wave tube [22-25]. The channel of PDE is different from that of WRC. For PDE, one end of the channel is closed and the other end of the channel is opened during combustion. For WRC, the two ends are all closed during combustion. The flow and combustion in the channel of a WRC are different from them in the channel of the WRC. The results of PDE with the spoilers could not be directly used for WRC. The combustible mixture flow is in the same direction as the flame propagation in the channel of PDE, but it is just the opposite in the channel of a WRC. Therefore, the investigation of pressure rise and flame acceleration in a single channel of a wave rotor combustor with spoilers should be performed.

In this study, the effects of some spoilers with different blockage ratios on the pressure rise and flame propagation in a single channel of a WRC were examined. Compared with current main WRC research which focuses on single-cycle and single-channel WRC, our study conducted tests on multicycle and single-channel WRC experimental rig using ethylene as fuel to determine the combustion characteristics of the WRC with some spoilers of different blockage ratios $(0,23.5 \%, 31.13 \%$, and $38.91 \%)$ and to explore the effects of spoiler blockage ratios on the pressure rise and flame acceleration characteristics of the WRC.

\section{Experimental System and Method}

A WRC experimental rig consists of a hot jet generator, WRC, motor, fuel supply system, and data acquisition system, as illustrated in Figure 3. Inside the prechamber, a hot jet is generated by propane ignited by a spark plug, and sustained stable hot jets are formed to ignite the combustible fuel/air mixture in the channel of the WRC. Plates on both sides of the WRC are fixed and connected to the rotational axis of the motor and therefore rotate with the motor. A number of intake ports are located on the end plate, as shown in Figure 4, and the arrangement of ports is directly linked to the operation of the WRC. Two additional exhaust ports are set on the exhaust sealing disk, while some additional ports with a smaller radius are included to allow the hot jets enter the wave rotor channel, and $180^{\circ}$ ports are positioned to enable outflow from the wave rotor channel. The exhaust sealing disk is installed near the hot jet generator, and the intake sealing disk is installed near the motor. Only one $170^{\circ}$ port is set on the intake sealing disk to allow fuel/air mixture to flow into the wave rotor channel. The open position of the exhaust port is $38^{\circ}$ less than the intake port. When the wave rotor channel stops and the system is in operation, the WRC working environment is formed. Ethylene is used as fuel. After starting the experiment, the air source is opened 

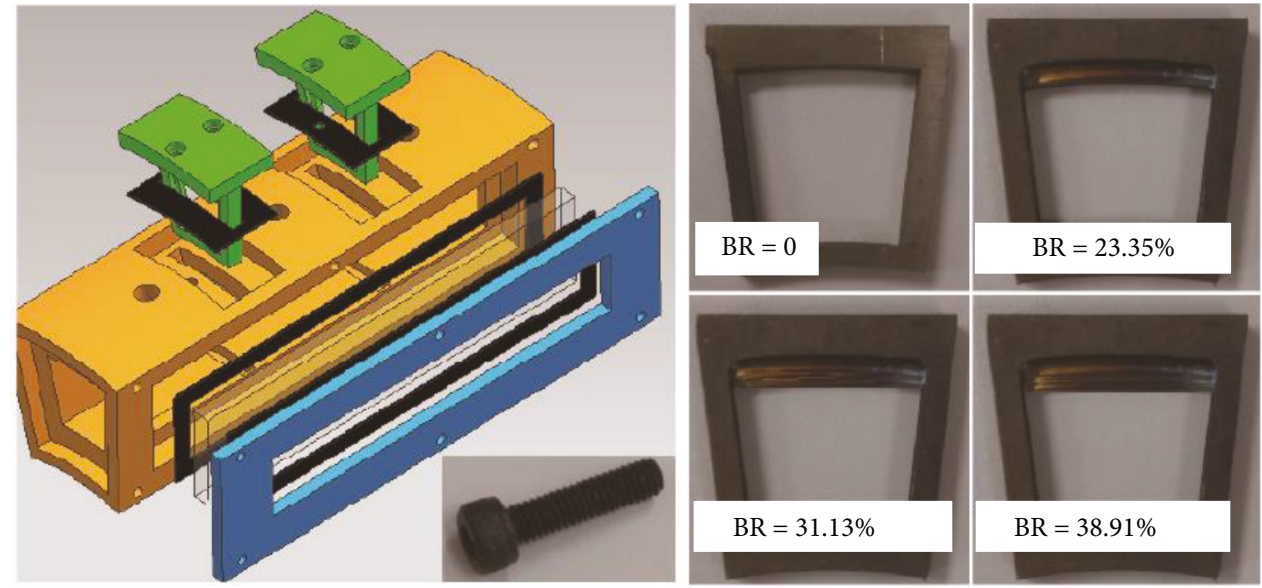

FIGURE 5: Illustration of a novel spoiler installation method in a channel of the WRC and spoilers with different blockage ratios.

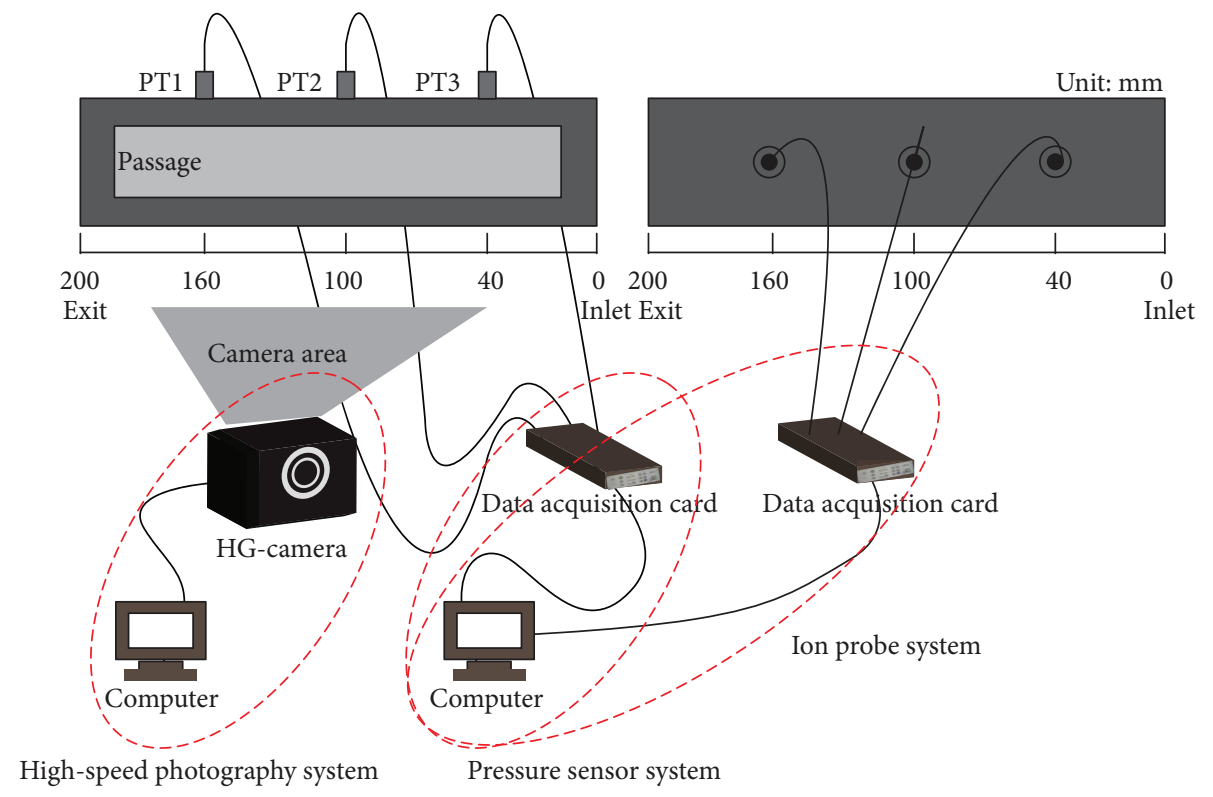

FIgURE 6: Schematic illustration of the data acquisition system.

for the hot jet ignitor which is turned on. Then, the motor is switched on and the speed is adjusted to $1200 \mathrm{rpm}$ until stable high-efficiency hot jets are formed. At the same time, the WRC air source is opened and the air flow rate and ethylene flow rate are adjusted to $47.669 \mathrm{~m}^{3} / \mathrm{h}$ and $1.6 \mathrm{~m}^{3} / \mathrm{h}$, respectively.

The design and installation of the spoilers is illustrated in Figure 5. There is relatively ubiquitous to install spoilers in the detonation combustor channels; however, WRC channels have particular structures with strict requirements. Therefore, spoiler guides must be fixed to the channel. These additional guides significantly affect the flow characteristics in a small channel of the WRC. A novel method is therefore developed in this study for installing the spoilers in a sizerestricted space. As illustrated in Figure 5, the spoilers are directly inserted into the seam of the upper wall surface. The spoiler is then bolted down. This drawer-like installation has numerous advantages including convenient installation and a simple structure with only minor influence on the external environment. The blockage ratio of a spoiler is defined as the area of the spoiler divided by the crosssectional area of the channel of the wave rotor. In this paper, the three spoilers with different blockage ratios $(23.5 \%$, $31.13 \%$, and $38.91 \%$ ) were designed for the WRC.

The data acquisition system of the WRC is comprised of a high-speed camera, pressure sensor system, and ion probe system, as illustrated in Figure 6. The high-speed camera is used to record the development of flame structures in a channel of the WRC at a frequency of $1000 \mathrm{~Hz}$. The length and width of the observation window are $153 \mathrm{~mm}$ and $26 \mathrm{~mm}$, respectively. By analyzing images taken at different time points by the camera, changes of the flame structure are observed; moreover, the time interval and flame propagation distance are determined by analyzing adjacent images. This method allows the flame propagation speed to be approximately measured in a relatively short time interval. Pressure 


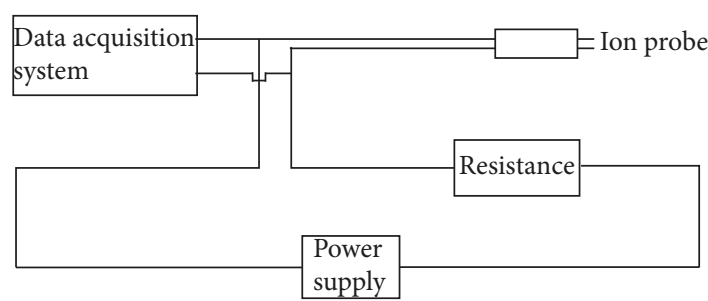

Figure 7: Schematic illustration of the ion probe system.

sensors (KD2004) with a sensitivity of $0.12 \mathrm{pC} / \mathrm{kPa}$, resonant frequency of $200 \mathrm{kHz}$, and sampling frequency of $500 \mathrm{kHz}$ were used to examine the pressure wave variations in a channel of the WRC, and ion probes were used to measure the variation of ion flow after combustion, which reflects the flame propagation characteristics. The pressure data by KD2004 sensor was compared with the data by PCB sensor $[26,27]$. The error is less than $5 \%$. The signal by ion probes was compared with that by photosensitive [28-30]. The error is less than $6 \%$. Signals were measured synchronously. Positions of the pressure sensors and ion probe are shown in Figure 6 . The inlet of the wave rotor is the origin coordinates (the starting point of the channel). More specifically, pressure sensors are located along the length of the pipe at $X=40 \mathrm{~mm}$, at $X=100 \mathrm{~mm}$, and at $X=160 \mathrm{~mm}$. The ion probe and pressure sensors are installed on the same cross-section but axially perpendicular.

The ion probe system was used to measure the propagation speed of flames in the channel of the WRC. The working principle can be described briefly as follows. It is well known that a large number of charged ions exist on the combustion flame surface. When a large number of charged ions gather around the ion probe, the ion probe is conductive, as shown in Figure 6. At that moment, ion probe and data acquisition system short circuits and the voltage dramatically drops, corresponding to the instant the flame arrives; therefore, the flame surface arrival time at the measuring point can thus be assessed using the acquired voltage signal. The ion probe system includes the ion probes, reasonable circuit, and data acquisition system, as shown in Figure 7. Under the nonconductive phase, the ion probe signal is $9 \mathrm{~V}$. As the flame surface moved toward the ion probe, the signal dropped, and the decreasing amplitude is related to the concentration of ions on the flame surface. At large ion concentrations, the detected signal is close to 0 . The signal detected by the pressure sensor represents the magnitude of pressure. The ion probes are arranged uniformly on the wall of the wave rotor. In the present experiment, due to space limitations, three ion probes are arranged to record the moment the flames arrive at the ion probe. Mean flame propagation speed is then be calculated by dividing the distance between two ion probes by difference in the arrival time. Measurements were performed several times, and average values were calculated.

\section{Characteristics of Pressure Rise and Flame Acceleration}

The acquired voltage and pressure signals collected by the ion probe and pressure sensors for WRC with the spoiler are shown in Figure 8, where the blockage ratio of the spoiler is $38.91 \%$. The data acquisition lasted $0.2 \mathrm{~ms}$ and the data acquisition frequency was set as $1 \mathrm{MHz}$ with a cut-off frequency of $1500 \mathrm{~Hz}$. It can be observed that the WRC underwent four operational loops and operated at a frequency of $20 \mathrm{~Hz}$ (corresponding to the WRC speed of $1200 \mathrm{rpm}$ ). The operating frequency of the WRC is identical to that of the motor, i.e., no frequency lag is observed. Furthermore, the signal for each cycle demonstrated good repeatability; indicating operation of the WRC is time sequence and normal.

Figure 9 presents the ion and pressure signals of a single cycle operation, which are the enlarged view of Figure 8. Overall, pressure is shown to rise earlier than the moment the ion probe signal is triggered (i.e., the flame arrival moment). During the flame propagation process, the distance between the initial pressure wave and flame surface is seen to increase, which can mainly be attributed to the greater propagation speed of the initial pressure wave compared to the flame. The peak of the pressure wave always remains in front of the flame. However, as the flame propagation accelerates, the pressure wave peak is seen to be closer to the flame, and the two values are almost coupled at ion probe 3 (IP3) and pressure transducer 3 (PT3), almost generating detonation combustion. Triggering of the flame signal is more evident than for the condition in front of the two positions. Ions released during the combustion process immediately result in a break in the probe, leading to a rapid decline in voltage signal. At IP3, the ion probe signal exhibited a small drop, suggesting the ions released from the combustion process are at a relatively low in concentration; moreover, the ion probe exhibited poor conduction capabilities, and the flame combustion rate is also low. After burning completely, the concentration of released ions drops, and the voltage signal detected by the ion probe rise again. Burning in the channel of the WRC starts when both sides of the channel are closed. In contrast, detonation would be achieved when one side of the channel is closed and the other side is open. Detonation is available to accelerate flame propagation whereas burning in the channel of the WRC is beneficial to the increase of voltage. To enhance dynamic performance, burning in the channel of the WRC exhibits more favorable performance with the pressure boost and high pressure is achieved in a shorter channel. At pressure transducer 1 (PT1), the pressure reaches $1.19 \mathrm{MPa}$; at pressure transducer 2 (PT2), the pressure peak exceeds $1.41 \mathrm{MPa}$; and at PT3, the peak pressure is close to $1.15 \mathrm{MPa}$. The pressure peak at PT3 is slightly lower than PT2 due to seal leakage in both the dynamic and static components of the WRC and near the port, and PT3 also exhibited a certain amount of leakage. It can be observed that the combustion pressure wave first increases and then decreases. As the combustion process progresses, pressure waves in the channel become superposed and propagate to PT3, which is close to the wave rotor channel port. The decline in pressure is due to some leakage at PT3. The voltage signal measured by the ion probe increases, and at PT1, the combustion process becomes intensified and the concentration of released ions is high. Accordingly, the ion probe exhibits favorable conductivity, and a huge voltage drop is observed. As the flame propagates toward the end of 



... . . lon signal

FIGURE 8: Signals collected by the ion probe and pressure sensors.

the channel, the flame propagation slows under the pressure of the front channel. Moreover, combustion of the combustible mixture in the channel is almost complete, combustion became less intense, and the ion probe exhibits weakened conductivity and a decrease in the voltage drop is observed.

In grayscale, images of the flames exhibit no obvious visual differences. Therefore, 16-color indexing was performed on the original grayscale images. The original grayscale images include information from 0 to 255 pixels, and the grayscale pixel values were divided into 16 intervals with each interval corresponding to a different color. The flame edge was also extracted. Pseudocolor flame images with a mesh size of $10 \mathrm{~mm}$ are displayed in Figure 10, where the blockage ratio of the spoiler is $31.13 \%$.

Figure 11 displays the flame structures at different moments in time. Combustion intensity is represented by brightness, where the blockage ratio of the spoiler is $31.13 \%$. During the flame propagation process, it is apparent that the flame propagation speed increases at the beginning then rapidly decreases as the flame propagates toward the end of the channel. During the acceleration process, since both sides of the wave rotor channel are closed, combustion products are enclosed, therefore, both the pressure and temperature following the combustion wave increase dramatically. Therefore, it can be concluded that the combustion wave is constantly being accelerated and the compressional wave is also intensified, thereby enhancing the pressure of the unburned combustible mixture in front of the flame, increasing the combustion rate, and forming a positive feedback effect. This is consistent with previously reported flame acceleration mechanisms $[31,32]$. In the late stages of the combustion process, flame propagation slows down and the compression wave in front of the flame is reflected by the closed end and reacts with the flame front, leading to a drastic decrease of the flame propagation speed. Furthermore, combustion is most intensive around the spoilers, as illustrated by brightness, shown in Figure 11. The turbulence around the spoilers is intensified, which accelerates the release of heat from the flame surface. Moreover, the flame surface is torn and stretched by strong turbulence, thereby increasing the heat release area from the flame, accelerating the thermal release rate of combustion, and enhancing the combustion intensity.

Table 1 presents variations of the pressure wave and flame during the combustion triggering process, wherein $\Delta t_{1}$ denotes the time difference between the time at which 


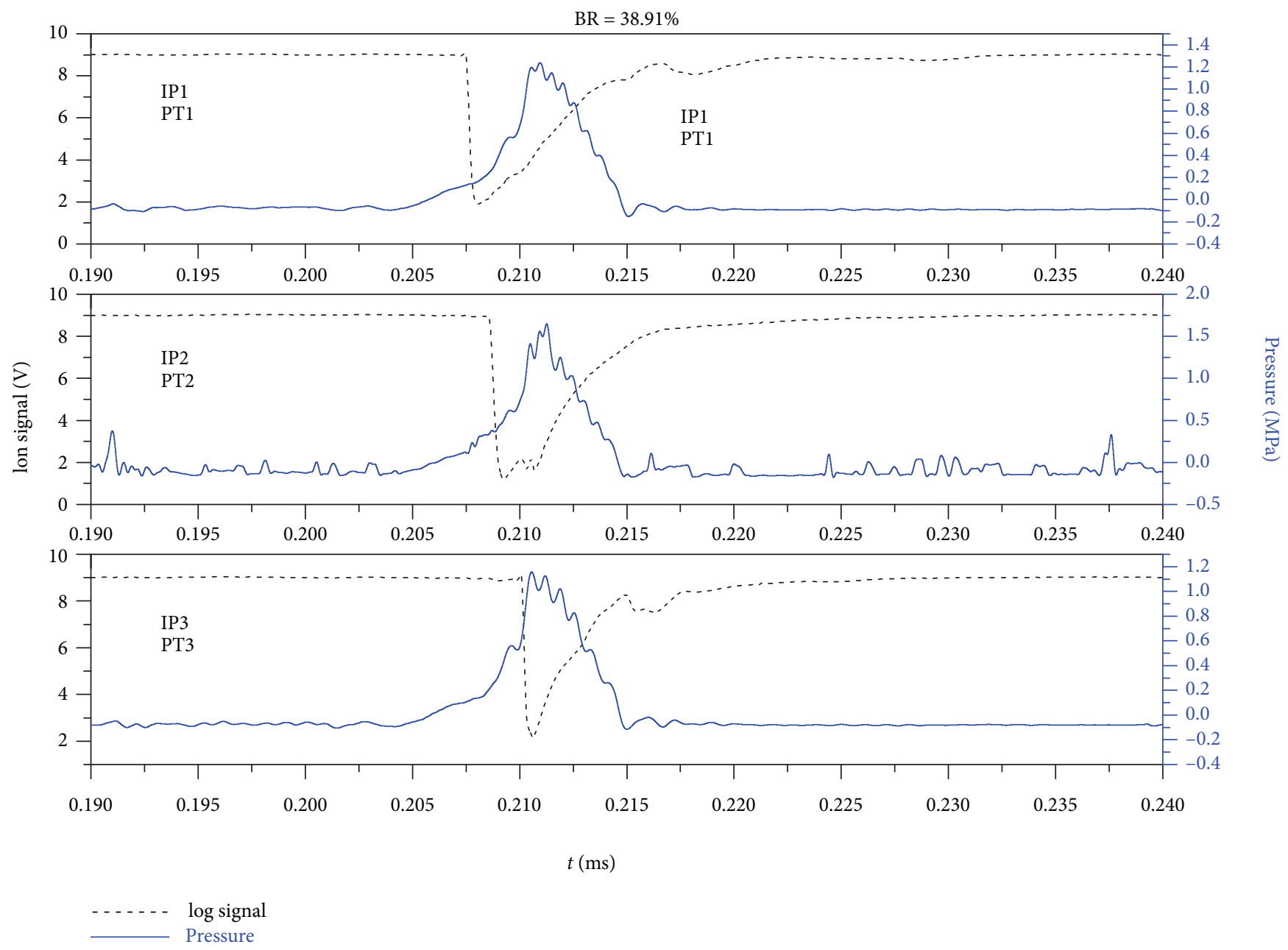

FIGURE 9: The ion and pressure signals of a single cycle operation.
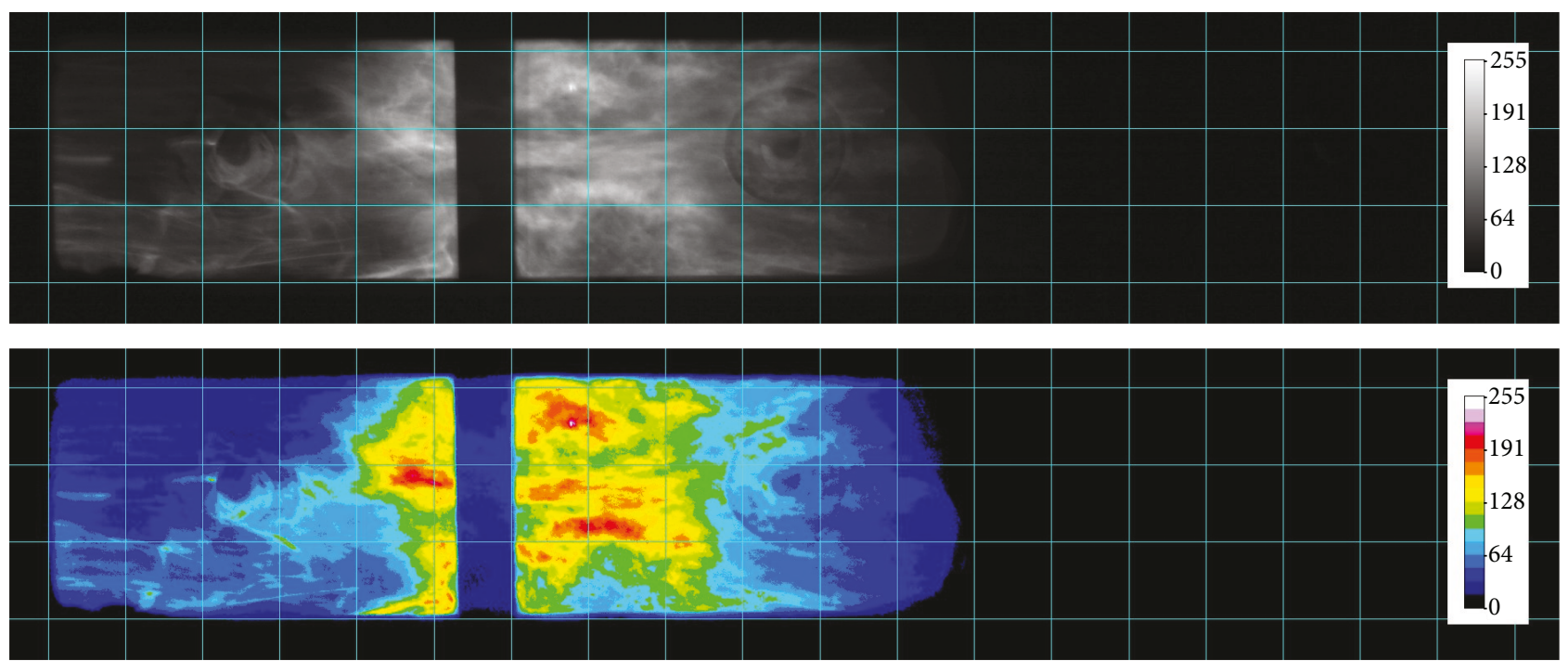

FIGURE 10: Grayscale-to-color processing of images taken using a high-speed camera $(B R=31.13 \%)$.

the flame was triggered and the peak of the ion probe signal occurred, $\Delta t_{2}$ denotes the time difference between the initial time and the moment at which the ion probe signal was restored to $95 \%$ of its initial value, $\Delta t_{3}$ denotes the time difference between the moment at which the initial pressure wave was triggered and the peak of combustion pressure 

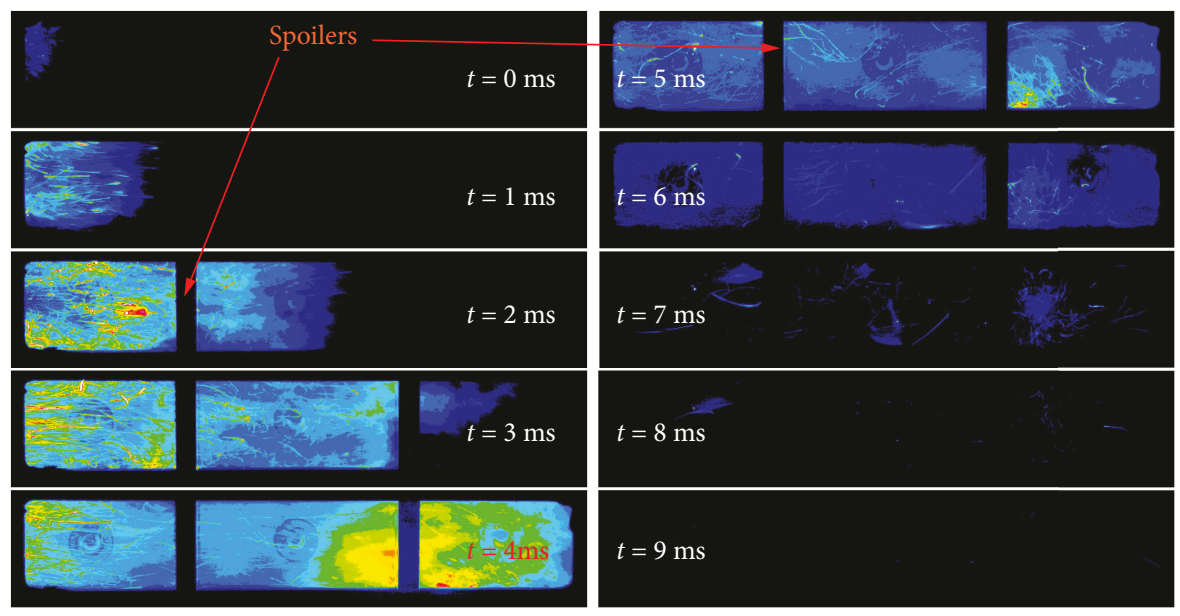

Figure 11: Variation of flame structure with time $(B R=31.13 \%)$.

TABLE 1: Triggering process of wave and flame.

\begin{tabular}{lcccccccccccc}
\hline Position & \multicolumn{4}{c}{ Parameters about flame propagation } & \multicolumn{4}{c}{ Parameters about pressure wave } \\
$\begin{array}{l}\text { Location } \\
(\mathrm{mm})\end{array}$ & $\begin{array}{c}\text { Trigger } \\
\text { moment } \\
(\mu \mathrm{s})\end{array}$ & $\begin{array}{c}\text { Moment of } \\
\text { peak value }(\mu \mathrm{s})\end{array}$ & $\begin{array}{c}\text { Moment of signal } \\
\text { recover 95\% }(\mu \mathrm{s})\end{array}$ & $\begin{array}{c}\Delta t_{1} \\
(\mu \mathrm{s})\end{array}$ & $\begin{array}{c}\Delta t_{2} \\
(\mu \mathrm{s})\end{array}$ & $\begin{array}{c}\text { Peak } \\
\text { value } \\
(\mathrm{V})\end{array}$ & $\begin{array}{c}\text { Trigger } \\
\text { moment } \\
(\mu \mathrm{s})\end{array}$ & $\begin{array}{c}\text { Moment of } \\
\text { peak value }(\mu \mathrm{s})\end{array}$ & $\begin{array}{c}\text { Peak } \\
\text { pressure } \\
(\mathrm{MPa})\end{array}$ & $\begin{array}{c}\Delta t_{3} \\
(\mu \mathrm{s})\end{array}$ & $\begin{array}{c}\Delta t_{4} \\
(\mu \mathrm{s})\end{array}$ \\
\hline$X=40$ & 207.4 & 208.1 & 216.6 & 0.7 & 8.5 & 1.877 & 203.7 & 210.4 & 1.19 & 6.7 & 2.3 \\
$X=100$ & 208.5 & 209.2 & 216.9 & 0.7 & 7.7 & 1.225 & 203.9 & 210.4 & 1.41 & 6.5 & 1.2 \\
$X=160$ & 210 & 210.5 & 217.7 & 0.5 & 7.2 & 2.236 & 204.2 & 210.6 & 1.15 & 6.4 & 0.1 \\
\hline
\end{tabular}

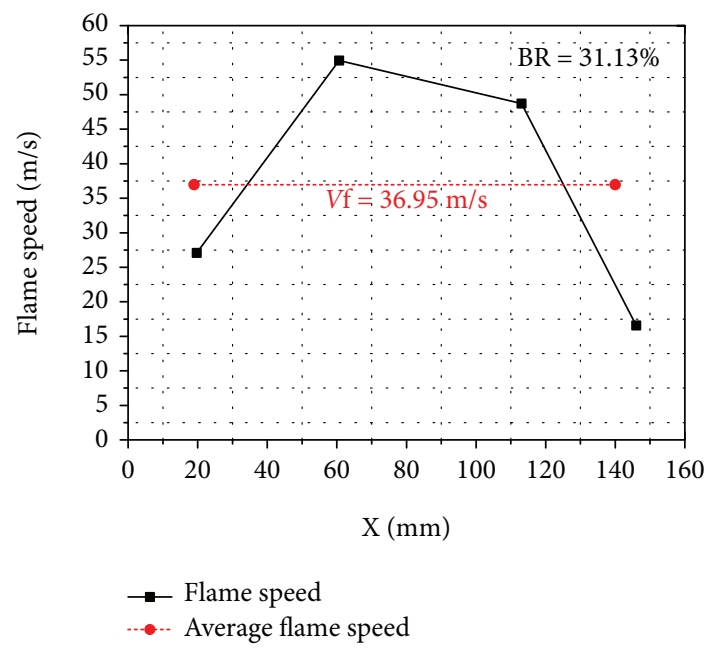

FIGURE 12: Flame propagation speeds at different positions in the combustion channel.

wave occurred, and $\Delta t_{4}$ denotes the time difference between the moment at which the peak of ion probe signal occurred and the peak of combustion pressure wave occurred. It can be observed that $\Delta t_{1}$ is the shortest at $X=100 \mathrm{~mm}$ within the channel suggesting the highest concentration of ions are released during combustion at this position, conductivity is most favorable, and the highest flame combustion rate occurs. Combining the results of Table 1 and Figure 9, it can be concluded that combustion at $X=100 \mathrm{~mm}$ in the channel is also intense. The duration of combustion is reflected in $\Delta t_{2}$, and the flame durations at $X=40 \mathrm{~mm}$, $100 \mathrm{~mm}$, and $160 \mathrm{~mm}$ decrease gradually. Superposition of the combustion pressure waves is reflected by $\Delta t_{3}$ and $\Delta t_{4}$ greater than zero, which suggests the pressure wave is always in front of the flame surface. Through comparison, $\Delta t_{4}$ increases gradually as $X$ increases steadily from $40 \mathrm{~m}$ to $160 \mathrm{~mm}$, which indicates that the distance between the flame surface and the initial pressure wave increases. In other words, the propagation speed of the pressure wave exceeds the propagation speed of flame. With accelerating flame propagation, the distance between the flame surface and the peak of the combustion pressure wave decreases. During this process, the flame chases the pressure wave and they become coupled resulting in detonation combustion.

The ion probe signal can be used to determine the variation of the flame propagation position with time to calculate the variation of flame propagation speed. However, since only a few ion probes were used, the flame propagation speed was instead calculated based on the images taken using the high-speed camera, as shown in Figure 12, where the blockage ratio of the spoiler is $31.13 \%$. Overall, the flame propagation speed exhibited three phases. In the first phase, hot jets flow into the wave rotor channel and ignite the premixed gas in the channel. During the initial propagation phase, the flame is mainly subjected to the impact of hot jets and accelerates. Next, upon encountering the spoilers, the flame is further accelerated. The turbulent intensity drops after the flame crosses the spoilers, which is accompanied by a decrease in the flame propagation speed. For WRC, the two ends are all closed during combustion. The directions of flow 


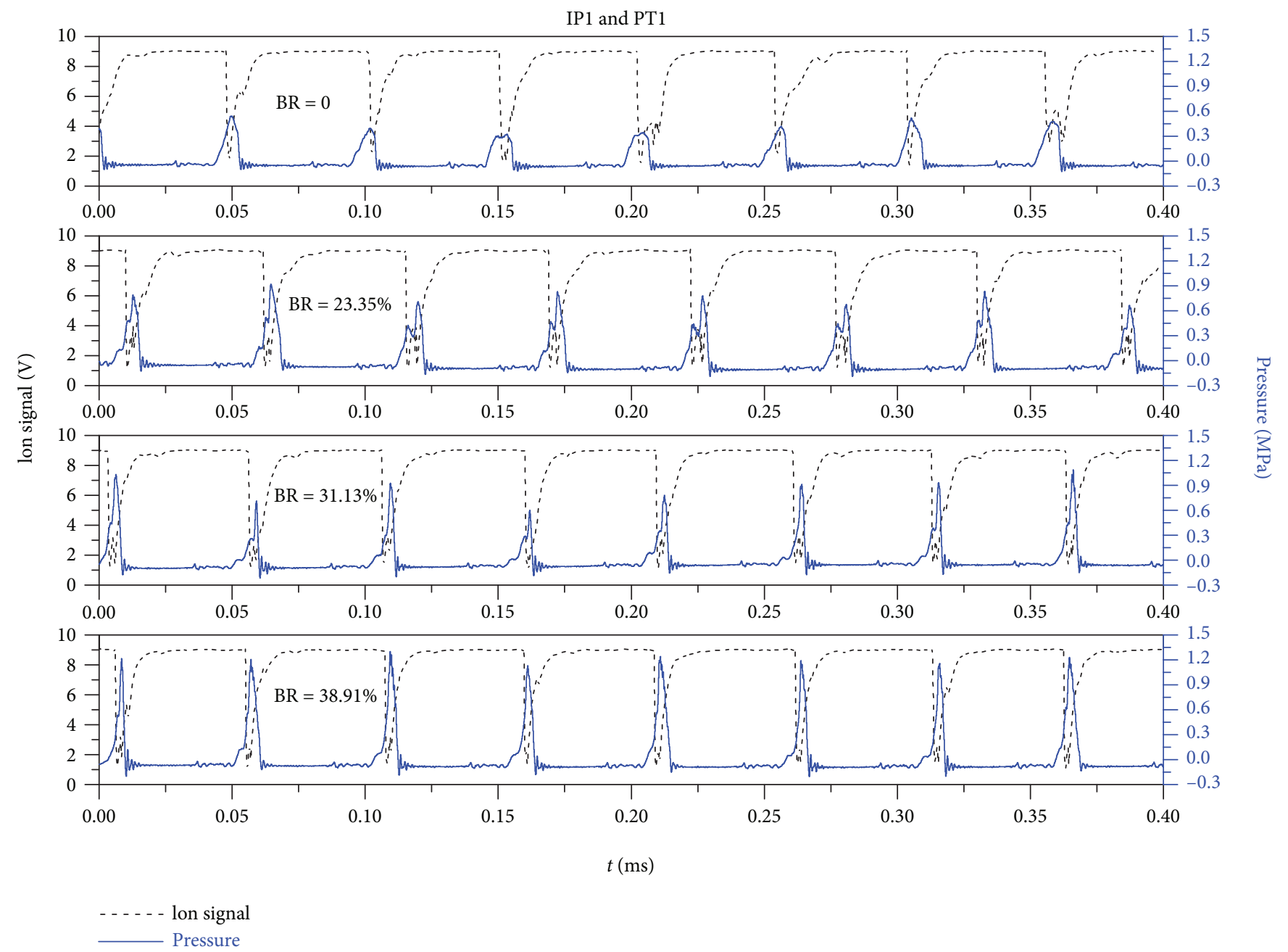

FIGURE 13: Variation of voltage (ion probe) and pressure signals (pressure sensor) at $X=160 \mathrm{~mm}$, where it is near the exit of the WRC with different blockage ratio spoilers.
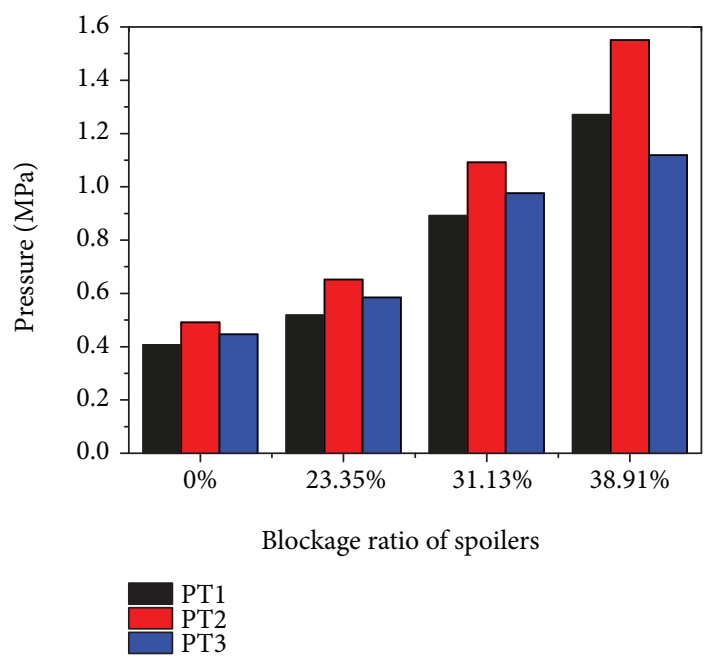

FIGURE 14: Peak pressures at different positions of the WRC with different blockage ratio spoilers. and flame propagation in the channel of the WRC are different in the channel of the WRC. The flame propagates upward the fuel/air mixture flow. After the inlet port closes, the fue1/air mixture flow also moves downward because of the inertia, which would induce the distribution of the fuel/air mixture near the inlet port to be not available for flame propagation. Using spoilers in the channel of the WRC, the flame propagation speed could be increased slightly. The combustion process in the WRC is not complete until the flame has propagated to the entire length of the channel. Throughout the entire combustion process, the maximum flame propagation speed is $55 \mathrm{~m} / \mathrm{s}$ with a mean value of $36.95 \mathrm{~m} / \mathrm{s}$, which are close to the speed of fast deflagration flame propagation $(15-44 \mathrm{~m} / \mathrm{s})$ in the channel of the wave rotor combustor by Asea Brown Boveri (ABB) in Switzerland [33].

\section{Effect of Spoiler Blockage Ratio on Pressure Rise and Flame Acceleration}

Experiments were performed to examine the effect of the spoiler BR on the combustion characteristics of the WRC during which the air intake and equivalence ratio of the 


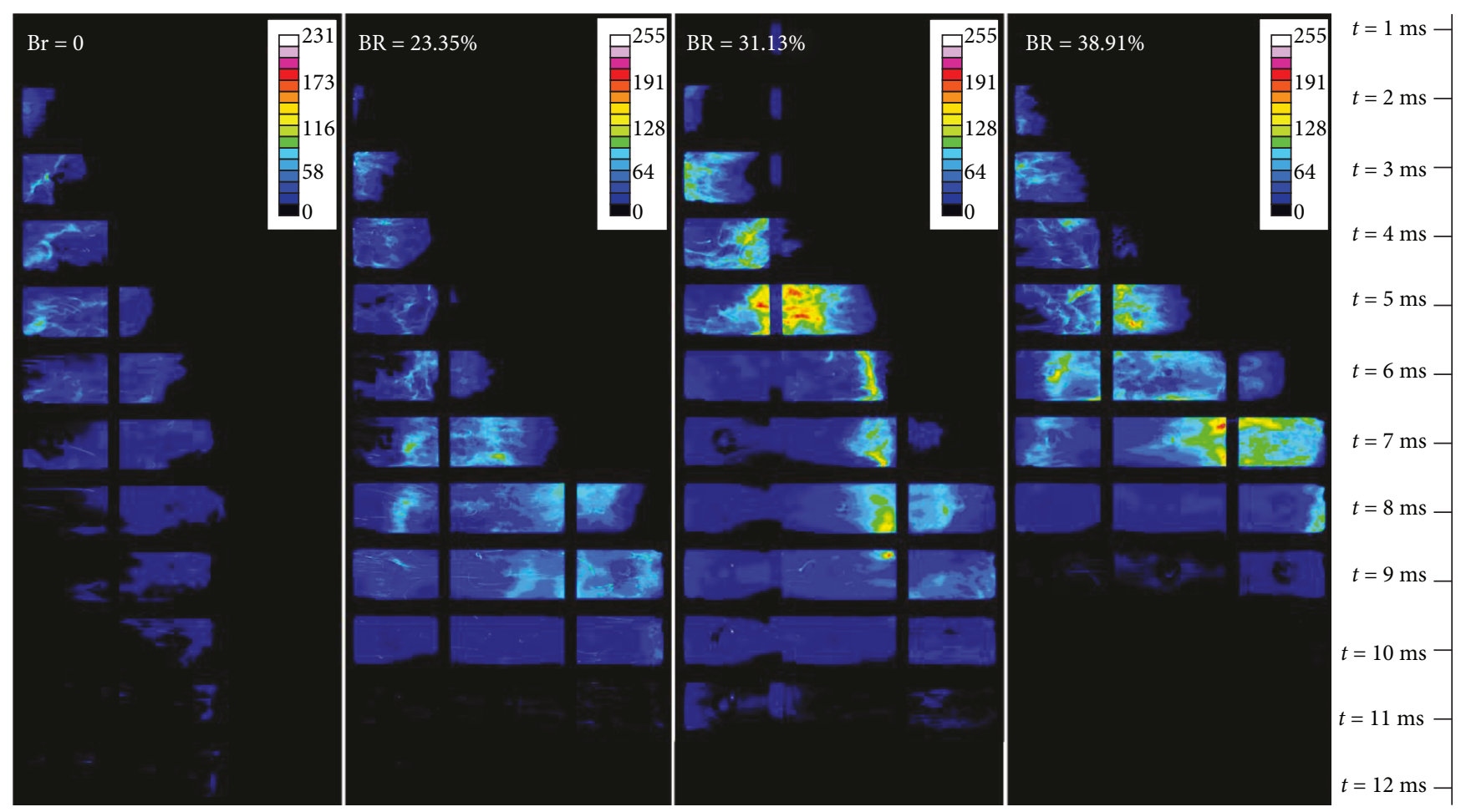

FIGURE 15: Flame propagation characteristics in the WRC with spoilers of different blockage ratio.

mixture were fixed. Spoilers with three different BRs were used ( $\mathrm{BR}=0,23.35 \%, 31.13 \%$, and $38.91 \%)$.

Figure 13 displays the variation of the signals collected by the ion probe and pressure sensor system at position $X=$ $160 \mathrm{~mm}$ (IP1 and PT1), where is near the exit of the WRC with different blockage ratio spoilers. The data is selected from 12 groups of voltage signals and pressure signals acquired by the ion probe and pressure sensor. Within a data acquisition time of $0.4 \mathrm{~ms}$, both the ion probe and pressure sensor acquired data across 8 cycles. The frequency is equal to the working frequency of the motor $(1200 \mathrm{rpm})$, and no frequency lag is observed, suggesting the WRC can work continuously through multiple cycles. When no flame surface is detected, the voltage detected by the ion probe is $9 \mathrm{~V}$. Once the flame surface is detected, the voltage signal drops. Most of the time, the pressure signal detected by the pressure sensor is lower than $0 \mathrm{MPa}$, corresponding to the period from discharge of the high-temperature burned gas from the channel of the WRC to the next working cycle. This is normal since low pressure forms in the channel of the WRC after discharging the high-temperature burned gas and the pressure increase after the fuel/air combustible mixture begins to fill for the start of the next cycle.

Variation of the peak combustion pressure of the WRC with different blockage ratio spoilers is shown in Figure 14. The data are the average value of the 12 sets of experimental results. By installing spoilers to the channel, the peak of the combustion pressure wave is significantly enhanced. When $\mathrm{BR}=38.91 \%$, the peak pressure at PT1 is enhanced by $200 \%$ compared to the no spoiler condition. This is due to the fact that the addition of spoilers enhances the combustion intensity, thereby increasing the peak of the maximum pressure wave during combustion. Moreover, as the blockage ratio of spoilers increases, the difference between the peak pressures at PT3 and PT2 also increases. The peak pressure at PT2 is the highest. The peak pressure at PT1 and PT3 is slightly lower, which suggests there is some pressure leakage [34]. With the blockage ratio of spoilers increasing, the pressure in the channel of the WRC also increases. Because of leakage from the port, some of the pressure rise value is lost. Differences between the peak pressures at PT1 and PT3 are slightly affected by leakage.

Figure 15 illustrates the flame propagation process in the channel of the WRC with different blockage ratio spoilers. The size of the inspection window is $153 \mathrm{~mm}$, which is smaller than that of the width of the wave rotor channel $(200 \mathrm{~mm})$, and therefore, a section of the wave rotor channel $23.5 \mathrm{~mm}$ away from the ignition end is not observed. Accordingly, the entire ignition process from when the hot jets enter the wave rotor channel cannot be acquired. Therefore, in this study, the time instant $1 \mathrm{~s}$ before the flame appears in front the inspection window was set as $t=0 \mathrm{~ms}$. It can be observed that, using spoilers with $\mathrm{BR}=0$, the flame does not cross whole channel. Instead, the flame stops at $t=9 \mathrm{~ms}$ and is discharged from the wave rotor channel at approximately $12 \mathrm{~ms}$. Based on this analysis, it can be observed that the exhaust port of the wave rotor channel opens at $t=9 \mathrm{~ms}$ and the intake port remains closed at that moment. The flame propagation speed is similar to the discharge speed of the fluid from the channel; therefore, the flame stagnates. At $t=$ $11 \mathrm{~ms}$, the intake port of the wave rotor channel opens so it can begin to fill with the fuel/air combustible mixture for 


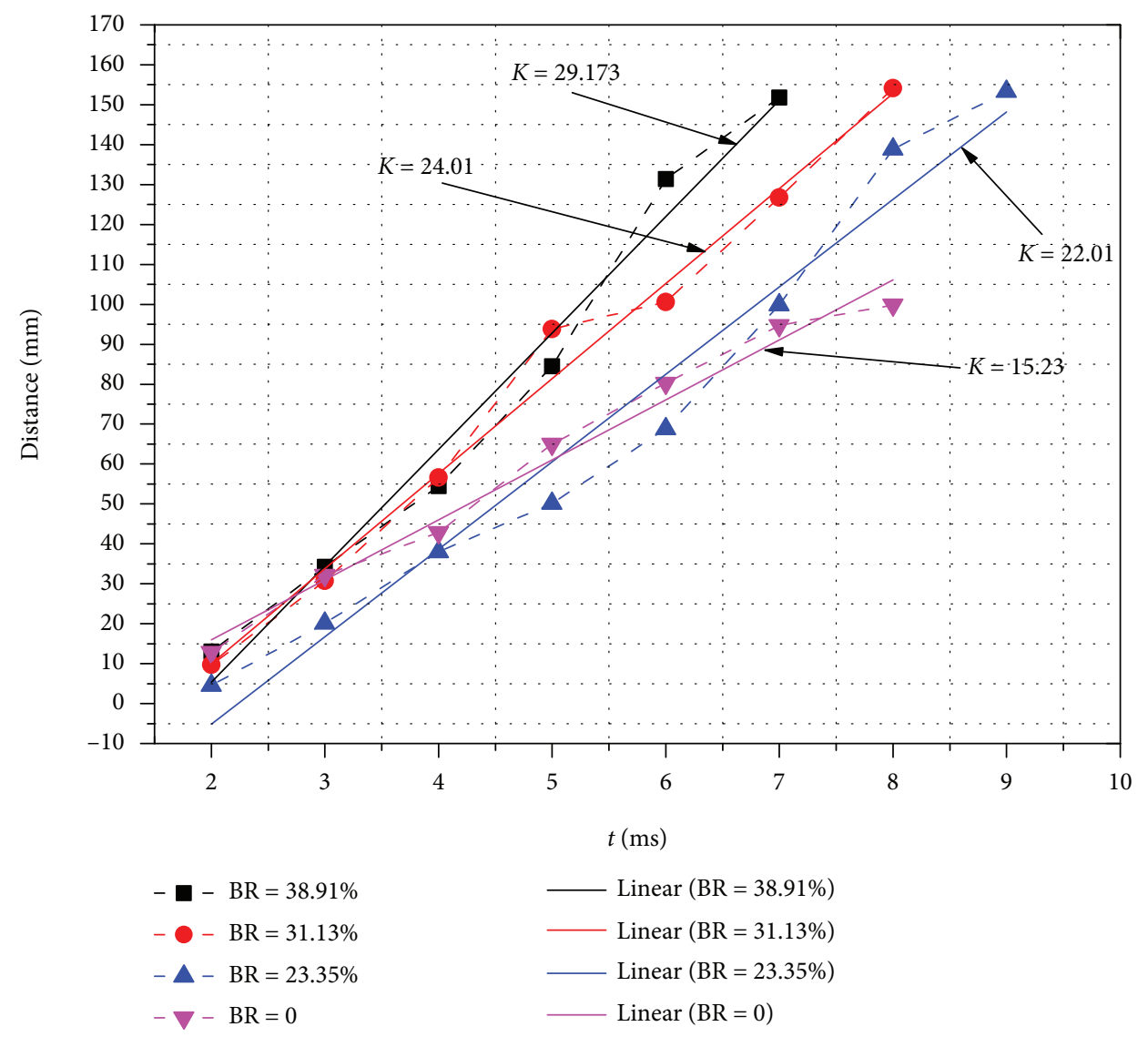

FIGURE 16: Variation of flame front position with time for WRC with different blockage ratio spoilers.

the next cycle. The filling speed of the fuel/air combustible mixture is $29.89 \mathrm{~m} / \mathrm{s}$, which exceeds the flame propagation speed, therefore, the flame is blown out of the wave rotor channel. As a result, a certain amount of fuel/air combustible mixture may be wasted, which can affect the performance of the WRC. When spoilers with $\mathrm{BR}=23.35 \%, 31.13 \%$, and $38.91 \%$ were used, the flame propagated through the whole channel, thereby confirming that the addition of spoilers accelerates flame propagation. In addition, combustion became more intense around the spoilers. The combustion intensity can be further enhanced by increasing the blockage ratio of the spoiler.

Variation of the flame front position over time with spoilers of different blockage ratio is shown in Figure 16, in which the solid lines represent the linear line of the best fit and slope $K$ denotes the mean flame propagation speed. When $\mathrm{BR}=0$, the maximum flame propagation distance can reach up to $99.67 \mathrm{~mm}$, which is almost $2 / 3$ of the length of the entire inspection window. Accordingly, the volume of the whole wave rotor channel cannot be fully utilized, which affects the performance of the WRC. When the spoilers of different blockage ratio $(23.35 \%, 31.13 \%$, and $38.91 \%$ ) are used, combustion flame could spread across the whole channel. The calculated slopes demonstrate that the mean flame propagation speed increases with increasing spoiler blockage ratio. Finally, when the blockage ratio of the spoilers used is $38.91 \%$, the mean flame propagation speed reaches $29.173 \mathrm{~m} / \mathrm{s}$.

\section{Conclusions}

An experimental rig for WRC with some spoilers of different blockage ratio was designed. The spoilers with different blockage ratio could be conveniently installed, disassembled, and altered. The spoilers are firstly used to improve the pressure in the channel of a WRC. Experiments were then conducted on the simplified system to examine the effect of the spoilers with different blockage ratio on the pressure rise and flame acceleration characteristics of the WRC. It is verified that the spoiler could improve the pressure rise and flame propagation speed. With the increasing of the blockage ratio, both the pressure rise and average flame propagation speed are increased. When the spoilers with the blockage ratio of $38.91 \%$ are used, the peak pressure of the WRC is enhanced by $200 \%$ compared to that of the WRC without the spoilers. When the spoilers with different blockage ratio are used, flame propagation speed increases significantly to a maximum flame propagation speed of $55 \mathrm{~m} / \mathrm{s}$ and mean flame propagation speed of $36.95 \%$. Combustion becomes more intense and the flame is brighter around the spoiler.

\section{Nomenclature}

WRC: Wave rotor combustor

BR: Blockage ratios

PDE: Pulse detonation engine

DDT: Deflagration-to-detonation transition 
PLIF: Planar laser-induced fluorescence

IP: $\quad$ Ion probe

PT: $\quad$ Pressure transducer

$\Delta t_{1}$ : Time difference between the time at which the flame was triggered and the peak of the ion probe signal occurred

$\Delta t_{2}: \quad$ Time difference between the initial time and the moment at which the ion probe signal was restored to $95 \%$ of its initial value

$\Delta t_{3}$ : Time difference between the moment at which the initial pressure wave was triggered and peak of combustion pressure wave occurred

$\Delta t_{4}$ : Time difference between the moment at which the peak of ion probe signal occurred and the peak of combustion pressure wave occurred

$X: \quad$ Location of pressure sensors

$K: \quad$ Slope of the linear line.

\section{Data Availability}

The data used to support the findings of this study are available from the corresponding author upon request.

\section{Conflicts of Interest}

The authors declare that they have no conflicts of interest.

\section{Acknowledgments}

This work was supported by "the National Natural Science Foundation of China,” No. 51476077.

\section{References}

[1] T. Elharis, S. Wijeyakulasuriya, M. Nalim, and Y. Matsutomi, "Analysis of deflagrative combustion in a wave-rotor constant-volume combustor," in 49th AIAA Aerospace Sciences Meeting Including the New Horizons Forum and Aerospace Exposition, 2011.

[2] J. Li, E. Gong, Q. Wen, and J. Wang, "Effect of internal combustion wave rotor technology on performance of gas turbine engine," Journal of Aerospace Power, vol. 27, no. 9, pp. 19281934, 2012.

[3] P. Akbari and N. Müller, "Performance improvement of small gas turbines through use of wave rotor topping cycles," in ASME Turbo Expo 2003, collocated with the 2003 International Joint Power Generation Conference, Atlanta, Georgia, USA, 2003.

[4] P. Akbari, R. Nalim, and N. Mueller, "A review of wave rotor technology and its applications," Journal of Engineering for Gas Turbines and Power, vol. 128, no. 4, pp. 717-735, 2006.

[5] J. Wilson and D. E. Paxson, "Wave rotor optimization for gas turbine engine topping cycles," Journal of Propulsion and Power, vol. 12, no. 4, pp. 778-785, 1996.

[6] V. Kilchyk, C. Merkle, and R. Nalim, "Effect of channel rotation on premixed turbulent combustion in a wave rotor combustor," in 43rd AIAA/ASME/SAE/ASEE Joint Propulsion Conference \& Exhibit, Cincinnati, OH, USA, July, 2007.

[7] J. Li, E. Gong, and W. Li, "Investigation on combustion properties in simplified wave rotor constant volume combustor," in 21st AIAA International Space Planes and Hypersonics Technologies, Xiamen, Fujian, March 2017.

[8] P. Akbari and R. Nalim, "Analysis of flow processes in detonative wave rotors and pulse detonation engines," in 44th AIAA Aerospace Sciences Meeting and Exhibit, Reno, Nevada, January 2006.

[9] J. Li, E. Gong, L. Yuan, W. Li, and K. Zhang, "Experimental investigation on pressure rise characteristics in an ethylene fuelled wave rotor combustor," Energy \& Fuels, vol. 31, no. 9, pp. 10165-10177, 2017.

[10] J. Li, E. Gong, L. Yuan, W. Li, and K. Zhang, "Experimental investigation on flame formation and propagation characteristics in an ethylene fuelled wave rotor combustor," Energy \& Fuels, vol. 32, no. 2, pp. 2366-2375, 2018.

[11] J. Li, L. Yuan, W. Li, and K. Zhang, "Numerical investigation of combustion characteristics of a wave rotor combustor based on a reduced reaction mechanism of ethylene," International Journal of Aerospace Engineering, vol. 2018, Article ID 8672760, 21 pages, 2018.

[12] G. Welch, S. Jones, and D. Paxson, "Wave rotor-enhanced gas turbine engines," Journal of Engineering for Gas Turbines \& Power, vol. 119, no. 2, pp. 469-477, 2013.

[13] A. Karimi, M. Rajagopal, and R. Nalim, "Traversing hot-jet ignition in a constant-volume combustor," Journal of Engineering for Gas Turbines and Power, vol. 136, no. 4, p. 041506, 2014.

[14] Y. Matsutomi, S. Meyer, S. Wijeyakulasuriya et al., "Experimental investigation on the wave rotor constant volume combustor," in 46th AIAA/ASME/SAE/ASEE Joint Propulsion Conference \& Exhibit, Nashville, TN, USA, July 2010.

[15] P. Chinnathambi, A. Karimi, M. Rajagopal, and M. Nalim, "Experimental study of traversing hot-jet ignition of lean hydrocarbon-air mixtures in a constant-volume combustor," 8th US National Meeting, Combustion Institute, vol. 13, pp. 94-97, 2014.

[16] R. Repaka, D. Singh, and G. Velidi, "Numerical investigation of unsteady detonation waves in combustion chamber using Shchelkin spirals," Carbon-Science and Technology, vol. 8, no. 3, pp. 18-28, 2016.

[17] J. Kasahara, K. Takazawa, T. Arai, and A. Matsuo, "Experimental study of impulse and heat transfer on pulse detonation engines," in 38th AIAA/ASME/SAE/ASEE Joint Propulsion Conference \& Exhibit, Indianapolis, Indiana, July 2002.

[18] T. P. Jenkins, S. T. Sanders, J. A. Baldwin, W. Fan, D. S. Baer, and R. K. Hanson, "Diode-laser based sensors for pulse detonation engine flows," in International Colloquium on Control of Detonation Processes, Moscow, Russia, July 4-7,2000.

[19] S. T. Sanders, T. P. Jenkins, J. A. Baldwin, D. S. Baer, and R. K. Hanson, "Diode-laser absorption sensor for measurements in pulse detonation engines," in 38th Aerospace Sciences Meeting and Exhibit, Reno, NV, USA, January 2000.

[20] S. Y. Lee, C. Conrad, J. Watts, R. Woodward, S. Pal, and R. J. Santoro, "Deflagration to detonation transition study using simultaneous Schlieren and OH PLIF images," in 36th AIAA/ASME/SAE/ASEE Joint Propulsion Conference and Exhibit, Las Vegas, NV, USA, 2000-3217.

[21] M. Cooper, S. Jackson, J. Austin, E. Wintenberger, and J. E. Shepherd, "Direct experimental impulse measurements for detonations and deflagrations," Journal of Propulsion and Power, vol. 18, no. 5, pp. 1033-1041, 2002.

[22] B. De Witt, G. Ciccarelli, F. Zhang, and S. Murray, "Shock reflection detonation initiation studies for pulse detonation 
engines," Journal of Propulsion and Power, vol. 21, no. 6, pp. 1117-1125, 2005.

[23] D. Zheng, J. Wang, H. Zhang, and W. Lin, "Effects of parameters of turbulence generator on the detonation wave in airbreathing gasoline-air pulse detonation engine," Journal of Propulsion Technology, vol. 25, no. 6, pp. 549-552, 2004.

[24] D. Zheng, J. Wang, B. Wang et al., "Experimental investigation on mechanism of swirling aerovalve and drag coefficient of turbulence generation in PDE," Journal of Nanjing University of Aeronauticser Astronautics, vol. 37, no. 1, pp. 101-105, 2005.

[25] D. Valiev, V. Bychkov, V.'y. Akkerman, C. K. Law, and L.-E. Eriksson, "Flame acceleration in channels with obstacles in the deflagration-to-detonation transition," Combustion and Flame, vol. 157, no. 5, pp. 1012-1021, 2010.

[26] P. Zhang, X. He, J. Li, and J. Zhang, "Experimental study on mechanism of shock-flame interactions in detonation tubes," Journal of Aerospace Power, vol. 22, no. 10, pp. 1617-1621, 2007.

[27] Y. Zhang, J. Wang, X. He, P. Zhang, Q. Han, and J. Zhang, "Reliability test in pressure measurement of detonation combustor," Journal of Aerospace Power, vol. 22, no. 10, pp. 1632-1638, 2007.

[28] P. Zhang, X. He, and J. Zhang, "Experiment on mechanism of flame evolution in detonation tubes," Journal of Propulsion Technology, vol. 29, no. 4, pp. 422-425, 2008.

[29] X. He and P. Zhang, "Investigation on the mechanism of wave and flame in the deflagration to detonation transition process," Journal of Aerospace Power, vol. 23, no. 11, pp. 2036-2042, 2008.

[30] X. He, P. Zhang, and J. Wang, "Experimental investigation of deflagration to detonation transition in two-phase mixture combustion," Journal of Propulsion Technology, vol. 26, no. 3, pp. 252-255, 2005.

[31] G. Ciccarelli, C. T. Johansen, and M. Parravani, "The role of shock-flame interactions on flame acceleration in an obstacle laden channel," Combustion and Flame, vol. 157, no. 11, pp. 2125-2136, 2010.

[32] G. Ciccarelli, C. J. Fowler, and M. Bardon, "Effect of obstacle size and spacing on the initial stage of flame acceleration in a rough tube," Shock Waves, vol. 14, no. 3, pp. 161-166, 2005.

[33] P. Akbari and R. Nalim, "Review of recent developments in wave rotor combustion technology," Journal of Propulsion and Power, vol. 25, no. 4, pp. 833-844, 2009.

[34] E. Gong, J. Li, B. Liu, and Q. Han, "Analysis of wave rotor combustor leakage and seal problems," Journal of Propulsion Technology, vol. 37, no. 10, pp. 1952-1957, 2016. 


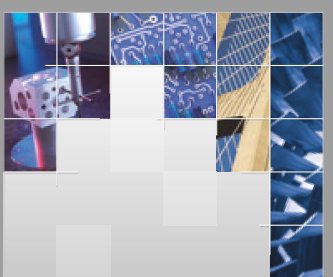

\section{Enfincering}
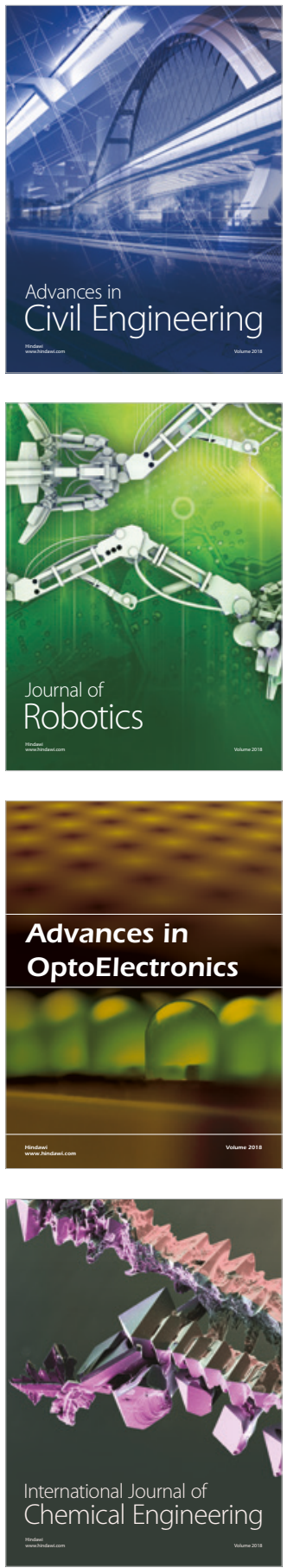

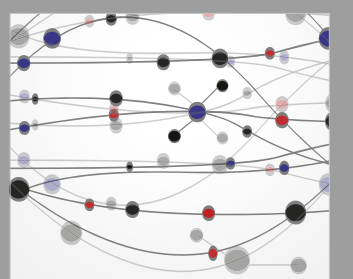

\section{Rotating \\ Machinery}

The Scientific World Journal

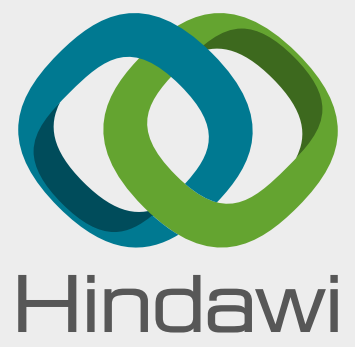

Submit your manuscripts at

www.hindawi.com
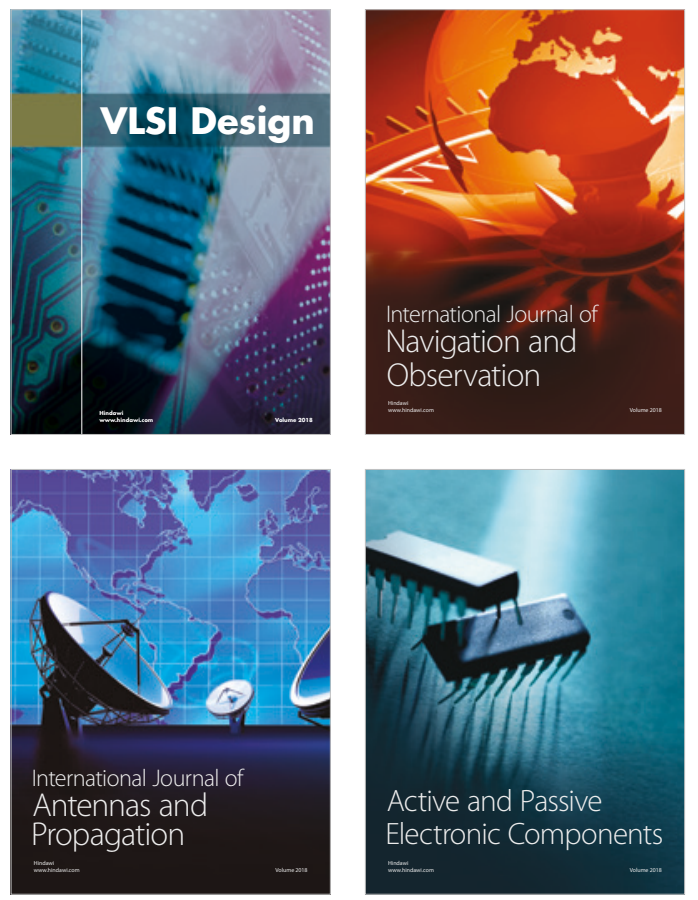
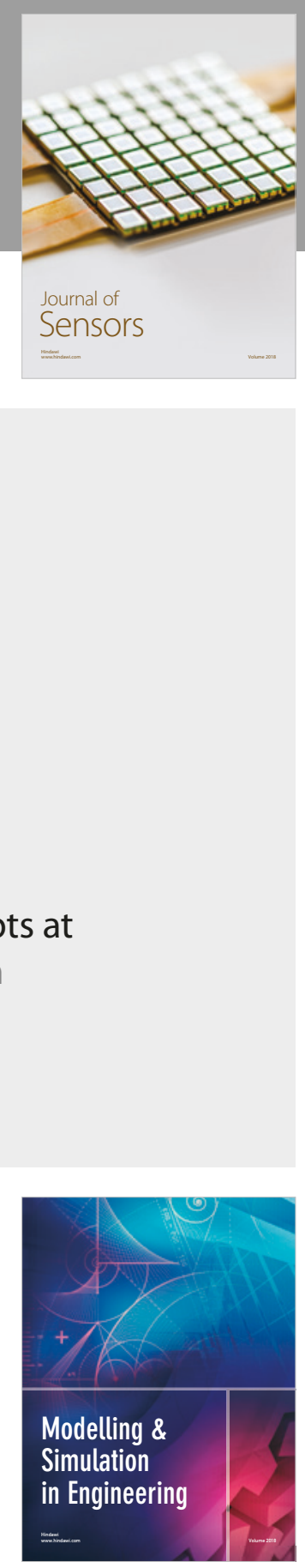

\section{Advances \\ Multimedia}
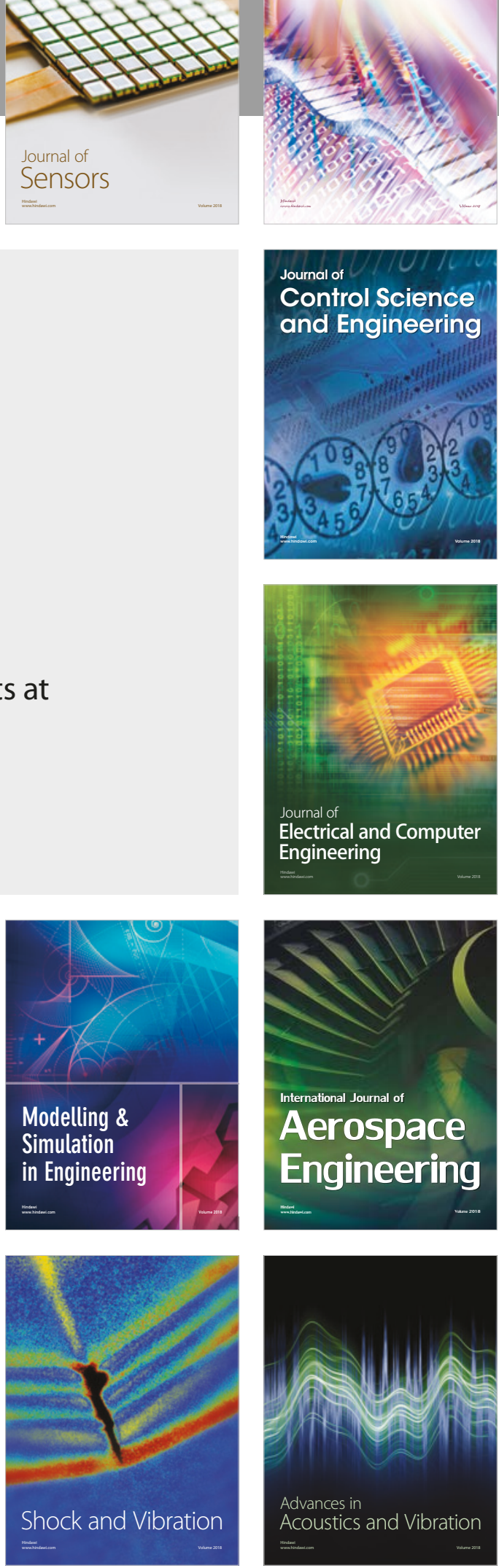